\title{
Diphenylhydantoin Induced DRESS Syndrome: A Case Report
}

\author{
Figen Leblebici, Özlem Soyal, Nevzat Mehmet Mutlu, Hatice Yağmurdur, Onur Karaca \\ Department of Anaesthesia and Intensive Care Unit, Ankara Numune Training and Research Hospital, Ankara, Turkey
}

Drug Rash with Eosinophilia and Systemic Symptoms" (DRESS) syndrome is a severe adverse drug reaction. The drugs most often implicated are anti-convulsants, bupropion, sulfonamides, sulfasalazine, allopurinol, minocycline, abacavir and neviparine. There are also immune and infectious causes that can lead to DRESS syndrome. A 70-year-old female patient had undergone endovascular coil embolization for intracranial aneurysm and experienced a generalised seizure postoperatively. She had been given diphenylhidantoin (DPH). Six days after DPH therapy, the patient had complained of widespread skin rash. Although DPH was replaced with levetiracetam afterwards, the skin rash deteriorated, causing facial oedema and swelling of the tongue. She had severe facial oedema with swelling of the tongue, causing disturbance of breathing. On the second day in the critical care unit, the patient's breathing deteriorated, leading successively to intubation and mechanical ventilation. The patient's rash was still persistent and the results of a punch biopsy taken from the lesions revealed superficial perivascular dermatitis involving spongiotic eosinophils compatible with spongiotic drug eruption. As a result, it is important to realise that medications we use can be the cause of a range of reactions ranging from simple rash to life threatening syndromes.

Key Words: Drug reactions, dress syndrome, diphenylhidantoin

\section{Introduction}

The term "Drug Rash with Eosinophilia and Systemic Symptoms" (DRESS) syndrome was first described in 1996 by Bocquet et al. (1) as a severe adverse drug reaction. The estimated incidence of this potentially life threatening syndrome was reported in a range from 1 in 1,000 to 1 in 10,000 drug exposures, with a mortality rate up to $10 \%$, mostly caused by fulminant liver failure. The clinical triad consists of fever, skin rash and internal organ involvement. The skin rash ranges from maculopapular rash to Stevens-Johnson syndrome and erythema multiforme. Laboratory tests usually show haematological disturbances including eosinophilia and atypical lymphocytes. Delayed onset of symptoms (2-6 weeks following culprit drug use) is an important feature of DRESS. The resolution of symptoms also takes a long time after causative drug withdrawal $(2,3)$.

The drugs most often implicated in DRESS are anti-convulsants, bupropion, sulfonamides, sulfasalazine, dapson, allopurinol, minocycline, abacavir and neviparine (2, 4-9). There are also immune and infectious causes such as human herpes virus 6 (HHV6) that can lead to DRESS syndrome (2, 10-14).

\section{Case Report}

A 70 year old female patient was admitted to the critical care unit with maculopapular rash and severe facial oedema with swelling of the tongue causing disturbance of breathing. About two weeks before admission to the critical care unit, the patient had undergone endovascular coil embolization for intracranial aneurysm under general anaesthesia. The patient had experienced a generalised seizure postoperatively. She had been given diphenylhidantoin (DPH) accordingly. Six days following DPH therapy, the patient had complained of widespread skin rash. Although DPH had been replaced with levetiracetam, the skin rash deteriorated, causing facial oedema and swelling of the tongue. The liver enzymes and renal function tests had also started to deteriorate on admittance to the critical care unit. 


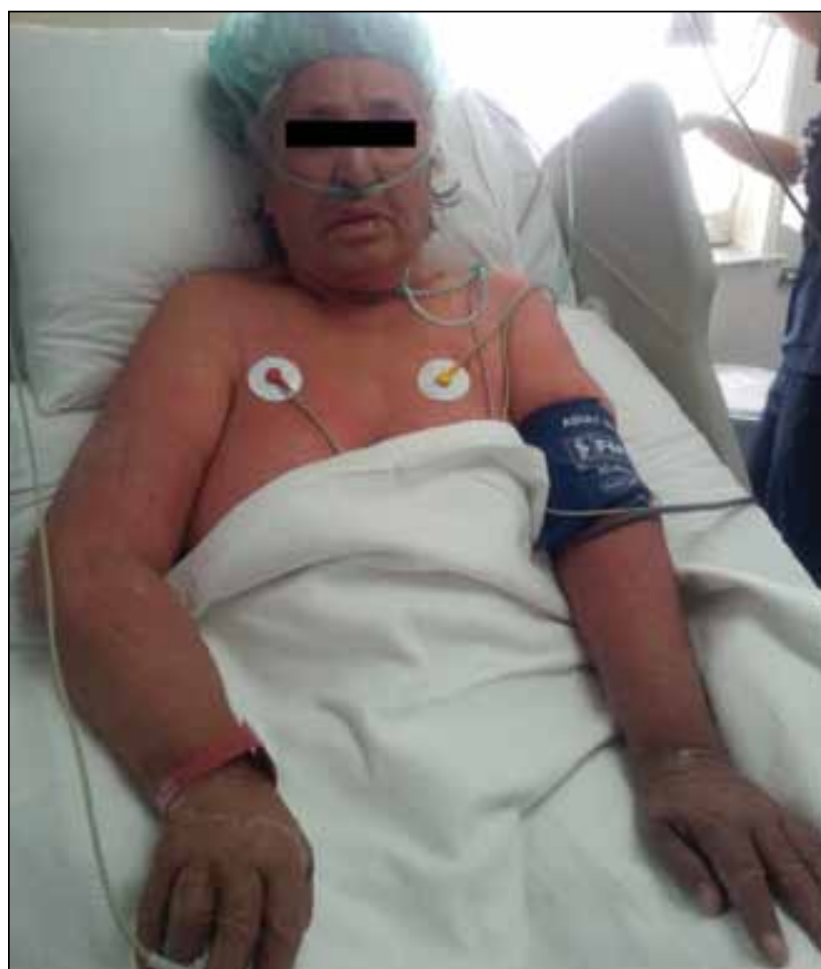

Figure 1. Diffuse erythema involving trunk and extremities, sparing palms of hands and feet, facial oedema, angioedema of the lips and tongue

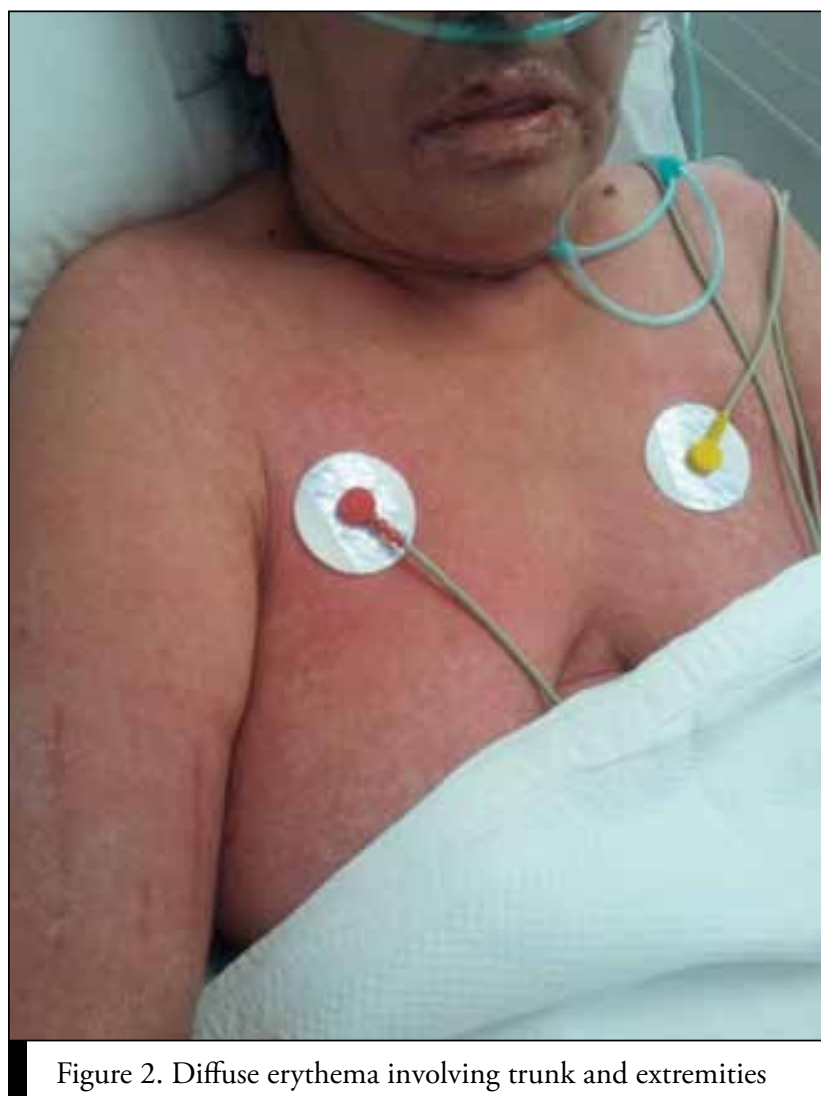

On physical examination at presentation, the patient had fever $\left(38.8^{\circ} \mathrm{C}\right)$, diffuse erythema involving trunk and extremities, sparing palms of hands and feet, facial oedema

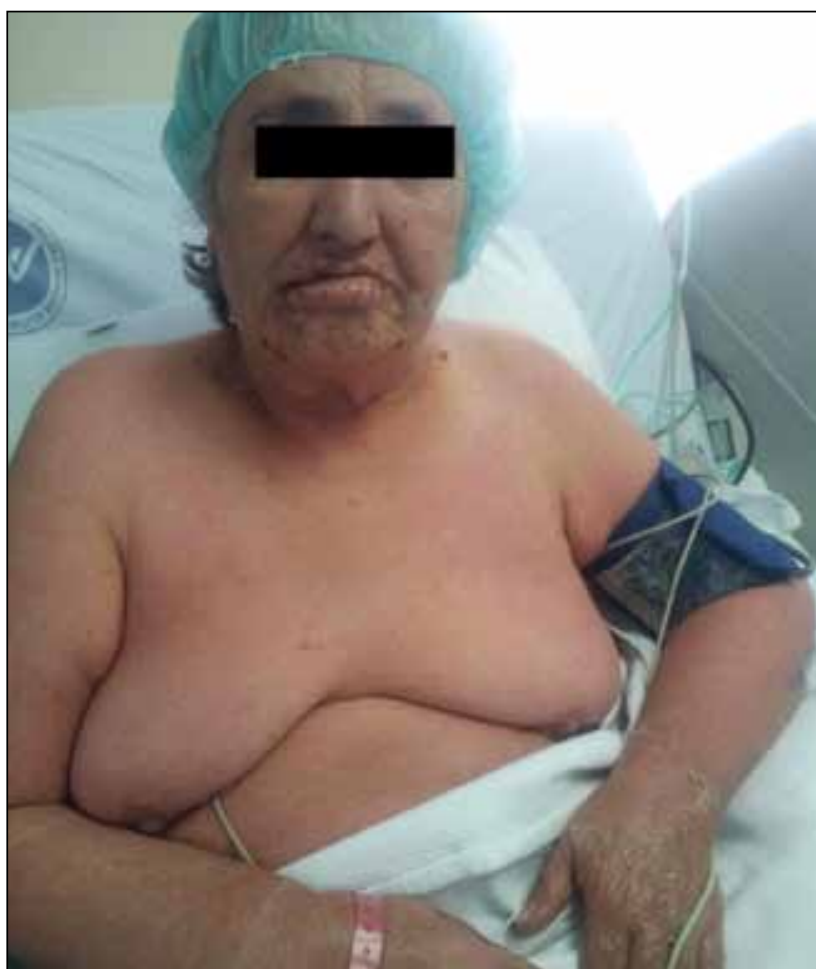

Figure 3. On the fifth day of intensive care, the patient's skin lesions started to fade

and angioedema of the lips and tongue (Figures 1,2). The laboratory findings on critical care arrival were as follows: WBC 17,000, PLT 335,000, Hb 10.5 gr dL $\mathrm{dL}^{-1}$, Htc 33\%, eosinophils $22.7 \%$, total bilirubin $0.6 \mathrm{mmol} \mathrm{L}^{-1}$, ALT $219 \mathrm{U} \mathrm{L}^{-1}$, AST $226 \mathrm{U} \mathrm{L}^{-1}$, GGT $1125 \mathrm{U} \mathrm{L}^{-1}$, LDH $1023 \mathrm{U} \mathrm{L}^{-1}$, CRP $114.67 \mathrm{mg} \mathrm{L}^{-1}$, BUN $82 \mathrm{gr}$, creatinine 1.47 $\mathrm{mg} \mathrm{dL}^{-1}$ and GFR $38 \mathrm{~mL} \mathrm{~kg}^{-1}$. The CBC revealed anisopoichilocytosis and eosinophilia. On the chest $\mathrm{x}$-ray there was thickening of the middle and lower peribronchial zones of the lung parenchyma. Abdominal ultrasound showed minimal enlargement of the spleen and liver from the midclavicular line. Ursodeoxycholic acid therapy was started due to the potential for toxic hepatitis. In consensus with the dermatology department, the patient was given $80 \mathrm{mg} \mathrm{day}^{-1}$ prednisolone.

On the second day of hospitalization in the critical care unit, the patient's breathing deteriorated, leading successively to intubation and mechanical ventilation. The patient's rash was still persistent and the results of the punch biopsy taken from the lesions revealed superficial perivascular dermatitis involving spongiotic eosinophils compatible with spongiotic drug eruption. Continuation of the prednisolone therapy until regression of the rash and cessation by reducing to a dosage of $10 \mathrm{mg}$ week $^{-1}$ was planned.

On the third day of hospitalization, E. coli was detected in the urine culture and Ceftriaxone $2 \times 1 \mathrm{gr}$ was given accordingly. On the fifth day of hospitalization, the patient's skin lesions started to fade and, as her respiration improved, she was ex- 
tubated the same day (Figure 3). The high fever, leucocytosis and eosinophilia were resolved (WBC count was 5,700 and eosinophilia rate was $2 \%$ ). Glomerular filtration rate was over 60, ALT 114, AST 57, GGT 592, LDH 567. Informed consent was obtained from the patient.

\section{Discussion}

DRESS is a serious reaction to drugs. Skin rash and involvement of organs vary, which make the diagnosis a real challenge. It is often confused with drug induced hypersensitivity reaction (2). In a literature review made from 133 reports between 1997 and 2009 with 44 drugs involved in 172 cases, a scoring system called RegiSCAR (European Registry of Severe Cutaneous Adverse Reactions) was used to define DRESS diagnosis as "definite case", "probable case", "possible case" or "no case" (6). One of the most frequently involved drugs, carbamazepine, was scored probable/definite. Cases with hypereosinophilia, fever and involvement of the liver were strongly probable for DRESS. Cessation of the implicated drug and use of steroids has both diagnostic and therapeutic value in these patients. Clinical symptoms usually occur 2-6 weeks following drug usage; however, they can take as long as 3-10 months and recovery is without sequelae after cessation of the drug $(2,6)$. In this case, clinical symptoms emerged 2 weeks after medication and continued even after cessation of the responsible drugs and steroid therapy. Accompanying infections and internal organ involvement increase mortality in DRESS. Our patient developed interstitial pneumonia and hepatitis. The eosinophil count was $17 \%$ on hospitalization and rose to $38 \%$ during follow up. All implicated drugs were stopped and corticosteroid therapy was started. Her urine cultures were positive and she was treated with ceftriaxone for seven days.

Although only partially understood, DRESS syndrome acts like a type 4 hypersensitivity reaction. HHV-6, HHV-7, CMV and EBV can be the cause as well $(2,7,11-14)$. HHV6 reactivation is a diagnostic parameter (15). Therefore serology must be checked. Although our patient's serology was negative, she developed perioral herpes and it vanished over time.

\section{Conclusion}

In conclusion, it is important to realise that medications we use can be the cause of a range of reactions from simple rash to life threatening syndromes. In such a condition, cessation of the implicated drug or drugs can be life saving.

Informed Consent: Written informed consent was obtained from patient who participated in this case.

Peer-review: Externally peer-reviewed.

Author Contributions: Concept - F.L.; Design - Ö.B.S.; Supervision - H.Y.; Data Collection and/or Processing - F.L., Ö.B.S., M.M.,
O.K.; Analysis and/or Interpretation - H.Y.; Literature Review M.M., O.K.; Writer - F.L.

Conflict of Interest: No conflict of interest was declared by the authors.

Financial Disclosure: The authors declared that this case has received no financial support.

\section{References}

1. Bocquet H, Bagot M, Roujeau JC. Drug-induced pseudolymphoma and drug hypersensitivity syndrome (Drug Rash with Eosinophilia and Systemic Symptoms: DRESS). Semin Cutan Med Surg 1996; 15: 250-7. [CrossRef]

2. Cacoub P, Musette P, Descamps V, Meyer O, Speirs C, Finzi L, et al. The DRESS syndrome: a literature review. Am J Med 2011; 124: 588-97. [CrossRef]

3. Fiszenson-Albala F, Auzerie V, Mahe E. A6-month prospective survey of cutaneous drug reactions in a hospital setting. Br J Dermatol 2003; 149: 1018-22. [CrossRef]

4. Vinson AE, Dufort M, Willis MD, Eberson CP, Harvell JI. Drug rash, eosinophilia, and systemic symptoms syndrome: Two pediatric cases demonstrating the range of severity in presentation--A case of vancomycin-induced drug hypersensitivity mimicking toxic shock syndrome and a milder case induced by minocycline. Pediatr Crit Care Med 2010; 11:38-43.

5. O'Meara P, Borici-Mazi R, Morton AR, Ellis AK. Dress with delayed onset acute interstitial nephritis and profound refractory eosinophilia secondery to vancomycin. Allergy Asthma Clin Immunol 2011; 3: 16. [CrossRef]

6. Kardaun SH, Sidoroff A, Valeyrie-Allanore L. Variability in the clinical pattern of cutaneous side-effects of drugs with systemic symptoms: does a DRESS syndrome really exist? Br J Dermatol 2007; 156: 609-11. [CrossRef]

7. Bakkal Uçal S, Koçak Tufan Z, Bulut C, Boyraz S, Vahaboğlu G. A case of DRESS syndrome mimicking sepsis. Klimik Journal 2011; 24: 132-4. [CrossRef]

8. Yücel A, Karakuş G, Günaştı S. Dermatologic side effects of psychotropic drugs and treatment approaches. Klinik Psikofarmakoloji Bülteni 2008; 18: 235-44.

9. Lindsay L, Oelze LL, Pillow MT. Phenytoin induced drug reaction with eosinophilia and systemic symptoms syndrome: a case report from the emergency department. J Emerg Med 2013; 44: 75-8. [CrossRef]

10. Yılmaz EA, Özmen S, Tuygun N, Giniş T, Tanır G. Lamotrigine associated Dress syndrome: A case report. Children Journal 2009; 9: 142-6.

11. Lerch M, Pichler WJ. The immunological and clinical spectrum of delayed drug-induced exanthems. Curr Opin Allergy Clin Immunol 2004; 4: 411-9. [CrossRef]

12. Shiohara T, Inaoka M, Kano Y. Drug-induced hypersensitivitysyndrome (DIHS): a reaction induced by a complex interplay among herpesviruses and antiviral and antidrug immune responses. Allergol Int 2006; 55: 1-8. [CrossRef]

13. Kano Y, Inaoka M, Shiohara T. Association between anticonvulsant hypersensitivity syndrome and human herpesvirus 6 reactivation and hypogammaglobulinemia. Arch Dermatol 2004; 140: 183-8. [CrossRef] 
Leblebici et al. DRESS Syndrome

14. Bossi P, Colin D, Bricaire F, Caumes E. Hypersensitivity syndrome associated with efavirenz therapy. Clin Infect Dis 2000; 30: 227-8. [CrossRef]
15. Tohyama M, Hashimoto K, Yasukawa M. Association of human herpesvirus 6 reactivation with the flaring and severity of drug-induced hypersensitivity syndrome. Br J Dermatol 2007; 157: 934-40. [CrossRef] 